\title{
Comparison of health efficiency between Pension security and Medical security for the elderly
}

\author{
Li Yang*, Chu Fuling \\ Central University of Finance and Economics, Beijing, China \\ *2017110057@email.cufe.edu.cn; chufuling@163.com
}

Keywords: Pension security, Medical security, Structural equation, Efficiency comparison

Abstract: Health issues have become one of the most important issues for the elderly in their later years. Especially with the aging of our country, "Healthy China" has become a hot issue for the government and academia. Based on the CLHLS 2014 survey data, this paper uses a structural equation model for analysis. The study found that both old-age security and medical security significantly improve the subjective health indicators of the elderly in their own evaluation of health, evaluation of health by others, health change, and life satisfaction. reducing two-week discomfort in the elderly and two years of severe illness indicators of objective health levels. In general, old-age security and medical security have improved the health of the elderly, but compared to old-age security, medical security produces better health efficiency. The possible reasons for this result are: firstly, the improvement of the health level brought by medical security is more intuitive. Secondly, the elderly's health needs remain at a lower level that can cure diseases, and the health benefits brought by old-age security are mainly reflected in disease prevention. Therefore, in guaranteeing the current level of medical security and the level of protection, we should vigorously develop old-age security, so that the elderly's focus on health level awareness is shifted to disease prevention, from passive treatment to active prevention, thereby improving the national health level.

\section{Introduction}

People's health has always been the focus of national attention. In 2016, the Outline of the "Healthy China 2030"Plan" was issued to propose specific phased goals for national health. At the same time, in the context of aging, old age health is particularly important. According to the National Bureau of Statistics, as of the end of 2017, the number of people aged 60 and over in the country exceeded 240 million, accounting for about $17.3 \%$ of the national population. In recent years, the government has always put health on the priority development strategy, and hopes to guide the elderly to actively pay attention to their own health, achieve prevention-oriented, combine prevention and treatment, and protect their own health from the source, and the government has increased its policy preferences to promote health Equalization of basic public services in the field, especially the targeted poverty alleviation policy provides basic social security for poor elderly people, and aims to reduce the level of health between urban and rural ,areas, regions. The elderly as a vulnerable group of society, the factors affecting its health are also more complex and diverse, 
and are subjective and objective factors intertwined. In terms of subjective reasons, the government mainly changes the public from passive acceptance to proactive prevention through active publicity and science popularization. In terms of objective reasons, the government needs to start from various aspects such as financial resources, material resources and services to achieve national health. Financially, in the first half of 2018, the financial subsidy to the basic pension insurance fund was 641.7 billion $\mathrm{CNY}$, and the financial subsidy to the basic medical insurance fund was 436.2 billion CNY. How can the state consider the role of endowment insurance and medical insurance in an all-round way under the condition of limited financial funds, adjust the proportion of funds invested in social insurance, and realize the maximum benefits of endowment insurance and medical insurance. In addition, the rapid development of commercial insurance has increasingly penetrated into people's lives and has also affected people's health. This article is based on comparing the efficiency of old-age security and medical security on the health of the elderly, hoping to provide a reference for the government to determine the proportion of old-age security and medical security investment in China's social security field, and also provide commercial insurance Purchase direction to protect their own health.

\section{Literature Review}

At present, domestic and foreign objective factors affecting the health of the elderly are mainly concentrated in the following three aspects.

The first is the impact of old-age security on elderly health. Liang J (2000) believes that pensions have a very important impact on the health of the elderly. Echevarria \& Iza (2006) explored the relationship between pension insurance rates and the health of the elderly. Zeng Xian xin (2007) believes that the existence of pensions has a significant impact on the risk of death for the elderly. Huang Feng and Wu Chun jie (2009) used the survey data of the factors affecting the health and longevity of the elderly in China from 2002 to 2005, and used the instrumental variable method to prove that the absence of medical insurance will lead to a higher probability of death for the elderly. Zhang Su et al. (2013) scholars used the 2011-2012 data of CHARLS and used the Probit model to find that the national pension insurance has a significant promotion effect on the health of the elderly. Wang Jun, Gong Qiang, and Wang Wei (2012) paid attention to the research on the relationship between the arrangement of pension insurance system and the health of the aging group, which reflected the change of research direction from the more simple concept of pension insurance to the concept of pension security system. The test results of Huang Jun (2017) article showed that: social security treatment, medical insurance, endowment insurance and the ADL loss rate of the elderly are significantly negatively correlated. Economic poverty and education are difficult to change the health level of the elderly in the short term. Treatment can bring appropriate and effective improvements to the health of the elderly population.

The second is the impact of medical security on elderly health. David Car (2008) and others showed that the old-age health insurance scheme did not have a significant effect on mortality through discrete regression methods. Huang Feng, Gan Li (2010) used Cox proportional hazard model to show that the risk of death is $19 \%$ lower for elderly people who enjoy medical insurance than for those without insurance; using the extended Kaplan-Meier survival function to estimate the average survival time, it is found The average age of the elderly is 5 years longer than that of the uninsured. Cutler and Vigdor (2005) found that the availability of medical insurance had no significant effect on the extent of health deterioration when affected by acute illness. Finkelstein \& Mc Knight (2008) stated that Medicare has been implemented in various states in the United States since 1965. It has also found that Medicare did not significantly reduce the mortality rate of people over 65 in the first 10 years of implementation. Wang Xinjun and Zheng Chao (2014) explored the 
impact of medical insurance on the medical expenditure and health level of the elderly. Levy \& Meltzer (2008) believes that research on causal effects of health insurance and health can only be explored by large-scale randomized experiments. Zhao Zhong and Hou Zhengang (2005) used the data of the China Health and Nutrition Survey to investigate the health influencing factors of urban residents in China, and found that medical insurance always showed a non-significant negative impact, which may be the estimation bias caused by missing explanatory variables in regression. Pan Jie et al. (2013) believe that the impact of urban residential security on residents' health is significant. And Wu Liancan, Shen Shuguang (2010) In the research on NCMS, most scholars have not found the health promotion effect of NCMS. H Wang (2009) studied the rural mutual medical insurance (RMHC) through experimental research, and found that RMHC significantly improved the health of rural residents, and increased the ability of individuals over 55 years to act and take care of themselves. At the same time, the self-reported pain and anxiety ratio of rural residents of all ages was reduced.

The third is the impact of other factors on elderly health. S Stringhini et al. (2010) proved that smoking is the most important mediator of socioeconomic status affecting health, and its impact is more significant than other mediating variables such as drinking and diet. Wilkinson (2010) and others believe that education can not only improve the level of personal knowledge, but also improve the recognition function. Therefore, receiving a good education will promote individuals to reduce the depreciation rate of health capital, and it is easier to develop a healthy lifestyle and achieve Accumulation of human capital. Sudhir Anand et al. (2001) analyzed the relationship between the self-reported two-week prevalence and the social and demographic characteristics of the respondents, and found that with the improvement of their educational level, the respondents were more likely to be aware of their physical condition May be more sensitive to disease and unhealthy conditions, which may increase the probability that they think they are sick, leading to an increase in self-reported prevalence for two weeks. Zhang Chong (2016) found that gender, age, marital status, medical insurance, smoking, drinking and other variables all have significant effects on the health of the elderly. Sirven and Debrand (2008) used European SHARE data from 2004 to study the impact of social participation on the health of groups aged 50 and over and found that social participation has a significant contribution to health. Liu Chang ping and Wang Lian jie (2017) found that the impact of education level, endowment insurance and medical insurance on the health of elderly people of different genders is quite different.

The above documents, starting from the impact of old-age insurance, medical insurance and other factors on the health of the elderly, affirmed the impact of old-age insurance, medical insurance and age, marriage, education, lifestyle and other aspects on the health of the elderly. However, as the two important parts of the people's livelihood, elderly care and medical care, comparative research on elderly care and medical care is scarce. With the advent of the silver tidal wave in our country, the health of the elderly has become a major test of our national livelihood. How to improve the health of the elderly with limited financial resources requires research. Based on previous studies, this paper uses a structural equation model to compare the effect of old-age security and medical security on the health level of the elderly in China, and hopes that China's policy formulation and implementation can be targeted.

\section{Research Design}

\subsection{Model Construction}

Based on the theories of predecessors and considering the factors that affect the health of the elderly, a health model for this paper was constructed. Health is a global problem that involves many factors. This article mainly compares the efficiency of old-age security and medical security 
on the health of the elderly, hoping to provide a reference for government policy formulation and preference. However, old-age security and medical security are only objective policy factors that affect the health of the elderly, and other factors such as daily living habits and education level are intertwined with each other to affect the health of the elderly. It can be seen that there are many factors affecting the health of the elderly, the mechanism is complex, and the structural equation model is needed for comparative measurement.

\subsection{Structural equation hypothesis}

Based on the structural equation model, this paper mainly constructs three structural indicators: physical condition, old-age security and medical security, which collectively affect the health of the elderly. At the same time, this paper divides the health of the elderly into two indicators: subjective health and objective health.

1) Physical conditions. There is no unified indicator for measuring physical conditions in China. This article refers to the international assessment indicators for self-care ability and is divided into basic daily living abilities (including the elderly's position change, indoor walking, eating, washing and grooming, dressing, bathing, toileting), Instrumental activities of daily living (including the ability of the elderly to go out and handle finances), cognitive abilities, and functional limitations (body part conditions). This paper uses the relevant questions in the questionnaire and uses the principal component analysis method to reduce the dimensionality to obtain the scores of the four dimensions. These four dimensions define the aspects of activity, cognition, and other aspects, and make a comprehensive and objective evaluation of the physical condition of the elderly.

2) Old-age security. As one of the five major social insurances, it provides guarantees for the elderly to survive their old age, and it also affects all aspects of the elderly's old age. This article mainly examines the old-age security of the elderly from the situation of pension insurance and the average income of the elderly. These two indicators cover both cash and services.

3) Medical insurance.As one of the five major social insurances, it eliminates the worries of diagnosis and treatment for the elderly, and reduces the possibility of the elderly becoming poor due to illness and returning to poverty due to illness. This article mainly examines the medical insurance situation, and the elderly's outpatient and inpatient expenses. These three indicators cover both cash and services. Outpatient and inpatient expenses almost cover most of the elderly's medical expenses .

4) Compared with others, everyone knows their basic conditions better. This article chooses the perception of the health and living conditions of the surveyed elderly from the perspective of the surveyed elderly, and hopes to obtain from different perspectives.

5) Objective health. From the perspective of actual behavior, the real situation of the elderly surveyed is used for evaluation. This article selected whether two weeks of physical discomfort and the number of severe illnesses within two years, these two indicators represent the actual health behavior of the elderly surveyed, the indicators are digitized, so that the objective health evaluation of the elderly is more scientific.

\subsection{Structural equation model and variables}

The structural equation model is a verification model, which is based on a certain theoretical basis. This paper chooses the structural equation model to compare the efficiency of pension insurance and medical insurance on the health of the elderly. The structural equation model includes two parts: a structural model and a measurement model.

$$
\eta=\mathrm{B} \eta+\Gamma \xi+\zeta
$$




$$
\begin{aligned}
& \mathrm{Y}=\Lambda_{y} \eta+\varepsilon \\
& \mathrm{X}=\Lambda_{x} \xi+\delta
\end{aligned}
$$

The equation (1) is a structural model, which means that the relationship between latent variables is established. In this paper, $\eta$ is set as two potential variables: subjective health $\eta_{1}$ and objective health $\eta_{2}$. Set $\xi$ as three explanatory potential variables of physical condition $\xi_{1}$, old-age security $\xi_{2}$ and medical security $\xi_{3}$. B represents the structural coefficient of the relationship between the two explained latent variables, namely subjective health and objective health, and $\Gamma$ represents the structural coefficient of the relationship between the explained latent variable and the latent variable. $\zeta$ is the prediction error (perturbation term) of the structural model.

Equation (2) is a measurement model that explains the latent variable $\eta$, and equation (3) is a measurement model that explains the latent variable $\xi$. (In formula (2), subjective health $\eta_{\_} 1$ is measured by 4 observation variables. Among them, $y_{1}$ is the evaluation of the health status of the elderly surveyed, $y_{2}$ is the evaluation of the health status of the elderly surveyed, $y_{3}$ is elderly Changes in a person's health status within a year, and $y_{4}$ is the elderly's evaluation of the current living status. Objective health $\eta_{2}$ is measured by 2 observation variables, of which $y_{5}$ is whether or not the patient is unwell within two weeks, and $y_{6}$ is the number of times when he / she has a serious illness (requiring hospitalization or being bedridden at home) within two years. $\Lambda_{y}$ is the factor load (regression matrix) between the observed variable and the latent variable being explained. $\varepsilon$ is the measurement error of the latent variable being explained. In the formula (3), the physical condition $\xi_{1}$ is measured by 4 observation variables, among which $x_{1}$ is an index of the elderly's daily activity ability, $x_{2}$ is an index of the elderly's instrumental daily activity ability, $x_{3}$ is an elderly functional limitation status indicator, and $x_{4}$ is cognitive function indicators for the elderly . Endowment insurance $\xi_{2}$ is measured by two observation variables, of which $x_{5}$ is the old-age insurance status of the elderly and $x_{6}$ is the average family income of the elderly. Medical insurance $\xi_{3}$ is measured by three observation variables, among which $x_{7}$ is the medical insurance status of the elderly, $x_{8}$ is the outpatient expenditure within one year, and $x_{9}$ is the inpatient expenditure within one year. $\Lambda_{x}$ is the factor load (regression matrix) between the observed variable and the latent variable being explained. $\delta$ is the measurement error explaining the latent variable.

\subsection{Data Sources}

This article uses the Peking University Healthy Ageing and National Development Research Institute to jointly organize the China Elderly Health Influencing Factors Tracking Survey (CLHLS). The survey covers 23 provinces, autonomous regions, and municipalities across the country. The data is representative, and it is one of the commonly used databases for the elderly in China. Based on the variables in this article, elderly people aged 60 years and over were selected as samples in the 2014 survey data and the missing variables were deleted. The final sample size was 4268.

\subsection{Descriptive statistical analysis}

Due to the rapid development of commercial insurance in recent years, it has increasingly penetrated into people's lives, and the public is also deeply aware of the importance of insurance. Therefore, this article uses social insurance and commercial insurance as variables for old-age security and medical security.

Among them, outpatient, inpatient expenses (I have no medical treatment behavior), and family income (depending entirely on the child or other people's pension) may be zero, so use (income / 
expense +1 ) to take the natural logarithm method to ensure such samples Not missing. The smaller the values of life satisfaction, health change, other-rated health, and self-rated health, it proves that the elderly tend to be good in this problem state, that is, the higher the health level of the elderly.

Table1 Statistical description of variables

\begin{tabular}{|c|c|c|}
\hline \multirow{3}{*}{$\begin{array}{c}\text { Old-age } \\
\text { security }\end{array}$} & Variable & Variable description \\
\hline \multirow{2}{*}{$\begin{array}{c}\text { medical } \\
\text { insurance }\end{array}$} & Endowment insurance & $\begin{array}{c}\text { Virtual variable. There is 1 for endowment } \\
\text { insurance and 0 for no endowment insurance. }\end{array}$ \\
\cline { 2 - 3 } & Medical insurance & ln(per capita income in the past year+1) \\
\cline { 2 - 3 } & Outpatient expenses & $\begin{array}{c}\text { Virtual variable. With medical insurance is 1 and } \\
\text { without medical insurance is 0. }\end{array}$ \\
\cline { 2 - 3 } $\begin{array}{c}\text { Subjective } \\
\text { health }\end{array}$ & Hospital expenses & ln(outpatient expenditure for the past year+1) \\
\cline { 2 - 3 } & Self-rating health & $\begin{array}{c}\text { Virtual variable. Very good is 1, good is 2, generally } \\
\text { 3, bad is 4, and very bad is 5. }\end{array}$ \\
\cline { 2 - 3 } & Others comment on health & $\begin{array}{c}\text { Virtual variable. Fair health is 1, comparative health } \\
\text { is 2, health is 3, and frailty is 4. }\end{array}$ \\
\cline { 2 - 3 } & Health change & $\begin{array}{c}\text { Virtual variable. Very good is 1, good is 2, generally } \\
\text { 3, bad is 4, and very bad is 5. }\end{array}$ \\
\cline { 2 - 3 } & Life satisfaction & $\begin{array}{c}\text { Virtual variable. Very good is 1, good is 2, generally } \\
\text { 3, bad is 4, and very bad is 5. }\end{array}$ \\
\hline $\begin{array}{c}\text { Objective } \\
\text { health }\end{array}$ & Two weeks of discomfort & $\begin{array}{c}\text { Virtual variable. 0 for no discomfort and 1 for } \\
\text { discomfort. }\end{array}$ \\
\cline { 2 - 3 } & Number of severe illnesses in \\
two years & $\begin{array}{c}\text { Specific figures, long bedridden can not afford to } \\
88 .\end{array}$ \\
\hline
\end{tabular}

\section{Empirical analysis results}

\subsection{Structural equation model estimation results}

Based on the assumptions and data presented earlier, this paper uses a maximum likelihood parameter estimation method. The estimated results are shown in Table 2.

Part A of Table 2 reports the estimation results of the structural model. It can be seen that, firstly, the regression coefficient of endowment insurance on the subjective health of the elderly surveyed is -1.083 , which is significant at the level of $1 \%$, while the regression coefficient of medical security on the subjective health of the elderly surveyed is -17.945 , The level of $5 \%$ is significant, indicating that the higher the level of old-age security and medical security, the better the elderly evaluates their health. The impact of old-age security is weaker than medical security, but its significance is better. The reasons are as follows: First, the old-age security has raised the income level of the elderly to a certain extent, reduced the probability of poverty, increased the subjective welfare of the elderly, and also made the elderly tend to make good evaluations of their own health. However, medical insurance has reduced the relative price of medical and health services to a certain extent, increased the accessibility of medical services, and thereby improved the health of the elderly. Greatly improved, the demand for health still stays at the level of primary needs that can be treated. In this article, self-assessment of health, other assessments of health, and health changes have a greater impact on subjective health. The health benefits of treatment-based health care for the elderly People are more intense, so the impact of medical security is stronger. Third, the sample size of the variables of medical insurance in the sample in this article is large, which may be a factor affecting the significance of medical security. Second, the regression coefficient of old-age security for the objective health of the elderly surveyed is -0.2 , which is significant at the level of $1 \%$, while 
the regression coefficient of medical security for the objective health of the elderly surveyed is -5.6, and at $5 \%$. The level is significant, indicating that the higher the level of old-age security and medical security, the better the elderly's objective health, the less ill and severe illness, but the impact of old-age security is weaker than medical security and its significance is better. The reasons are as follows: First, the old-age security guarantees the elderly's economic income in old age, provides economic security for the elderly to treat diseases, and the medical security is a direct reduction and exemption of medical expenses, which enables most elderly people to achieve illness without delay and reduce The elderly are unwell and seriously ill; the second is that although the living standards of the elderly have been improved, it has not been long, and their awareness of disease prevention has also taken off soon. The treatment benefits brought by medical insurance are more intuitive than the pension insurance Therefore, the impact of medical security is stronger. Third, the impact of medical security is less significant than that of old-age security. The reasons may be similar to the reasons for subjective health.

As a latent variable as a control variable, the impact of physical condition on subjective health and objective health is significantly positive at the level of $1 \%$, which indicates that the poorer the physical condition of the elderly surveyed, the lower their subjective evaluation of their health, and the physical discomfort And the greater the probability or the greater the number of serious illnesses, this is in line with the research of many scholars and the public's perception.

Table 2 Structural equation model parameter estimation results $(\mathrm{N}=4628)$

\begin{tabular}{|c|c|c|c|c|}
\hline Model & Variable relationship & $\begin{array}{l}\text { Estimated } \\
\text { coefficient }\end{array}$ & $\begin{array}{c}\text { Standard } \\
\text { error }\end{array}$ & $\mathrm{P}$ \\
\hline \multirow{6}{*}{$\begin{array}{l}\text { A. } \\
\text { Structural model }\end{array}$} & Old-age security $\rightarrow$ Subjective health & -1.083 & 0.152 & $0.000 * * *$ \\
\hline & Old-age security $\rightarrow$ Objective health & -0.200 & 0.048 & $0.000 * * *$ \\
\hline & Physical conditions $\rightarrow$ Subjective health & 0.231 & 0.011 & $0.000 * * *$ \\
\hline & Physical conditions $\rightarrow$ Objective health & 0.072 & 0.005 & $0.000 * * *$ \\
\hline & Medical security $\rightarrow$ Subjective health & -17.945 & 8.050 & $0.026^{* *}$ \\
\hline & Medical security $\rightarrow$ Objective health & -5.600 & 2.532 & $0.027 * *$ \\
\hline \multirow{15}{*}{$\begin{array}{l}\text { B. Measurement } \\
\text { model }\end{array}$} & Physical conditions $\rightarrow$ Daily activity & $1^{a}$ & & \\
\hline & $\begin{array}{l}\text { Physical conditions } \rightarrow \text { Instrumental daily } \\
\text { activity }\end{array}$ & 1.553 & 0.030 & $0.000 * * *$ \\
\hline & Physical conditions $\rightarrow$ Limited function & 0.662 & 0.013 & $0.000 * * *$ \\
\hline & Physical conditions $\rightarrow$ Cognitive function & 0.990 & 0.030 & $0.000 * * *$ \\
\hline & Old-age security $\rightarrow$ endowment insurance & $1^{a}$ & & \\
\hline & Old-age security $\rightarrow$ personal income & 4.089 & 0.485 & $0.000 * * *$ \\
\hline & Subjective health $\rightarrow$ Self-rating health & $1^{a}$ & & \\
\hline & $\begin{array}{c}\text { Subjective health } \rightarrow \text { Others comment on } \\
\text { health }\end{array}$ & 0.919 & 0.031 & $0.000 * * *$ \\
\hline & Subjective health $\rightarrow$ Health change & 0.609 & 0.028 & $0.000 * * *$ \\
\hline & Subjective health $\rightarrow$ Life satisfaction & 0.508 & 0.024 & $0.000 * * *$ \\
\hline & $\begin{array}{c}\text { Objective health } \rightarrow \text { Two weeks of } \\
\text { discomfort }\end{array}$ & $1^{a}$ & & \\
\hline & $\begin{array}{c}\text { Objective health } \rightarrow \text { Number of serious } \\
\text { illnesses in two years }\end{array}$ & 25.783 & 1.861 & $0.000 * * *$ \\
\hline & Medical security $\rightarrow$ Medical insurance & $1^{a}$ & & \\
\hline & Medical security $\rightarrow$ Outpatient expenses & -200.035 & 88.623 & $0.024 * *$ \\
\hline & Medical security $\rightarrow$ Hospital expenses & -215.281 & 95.249 & $0.024 * *$ \\
\hline \multirow{3}{*}{$\begin{array}{l}\text { C. Fitting } \\
\text { indicators }\end{array}$} & \multicolumn{4}{|l|}{ GFI $=0.957 \quad$ AGFI $=0.933 \quad$ RMSEA $=0.064$} \\
\hline & \multicolumn{4}{|l|}{$\mathrm{NFI}=0.901 \quad \mathrm{IFI}=0.906 \quad \mathrm{CFI}=0.906$} \\
\hline & \multicolumn{4}{|l|}{ PGFI $=0.606 \quad$ PNFI $=0.652$} \\
\hline
\end{tabular}

Note: Non-standard coefficients are reported in the table. "a" is used to indicate the factor load of 
the first measurement index. The SEM defaults to $1 . *$ means significant at the $10 \%$ level, and ${ }^{* *}$ means at the $5 \%$ level. Significant below, ${ }^{* * *}$ means significant at the $1 \%$ level.

Part B of Table 2 reports the estimation results of the measurement model. The relationship between latent variables and observed variables was significant at the $1 \%$ level. This shows that the observed variables of the main latent variables of the structural equation model in this paper have a higher level of measurement.

Part C of Table 2 reports the fit results for the entire model. Among them, the absolute fitness index GFI, AGFI, and the value-added fitness index NFI, IFI, and CFI are greater than 0.90, and the comprehensive fitness index PGFI and PNFI are greater than 0.5, indicating a good degree of fit; when the RMSEA is less than 0.05, As the model is very reasonable, when the RMSEA is between 0.05 and 0.08 , the model is considered relatively reasonable. The model in this paper is in a relatively reasonable range, and its goodness of fit is acceptable, which can better reflect the impact of old-age security and medical security on health.

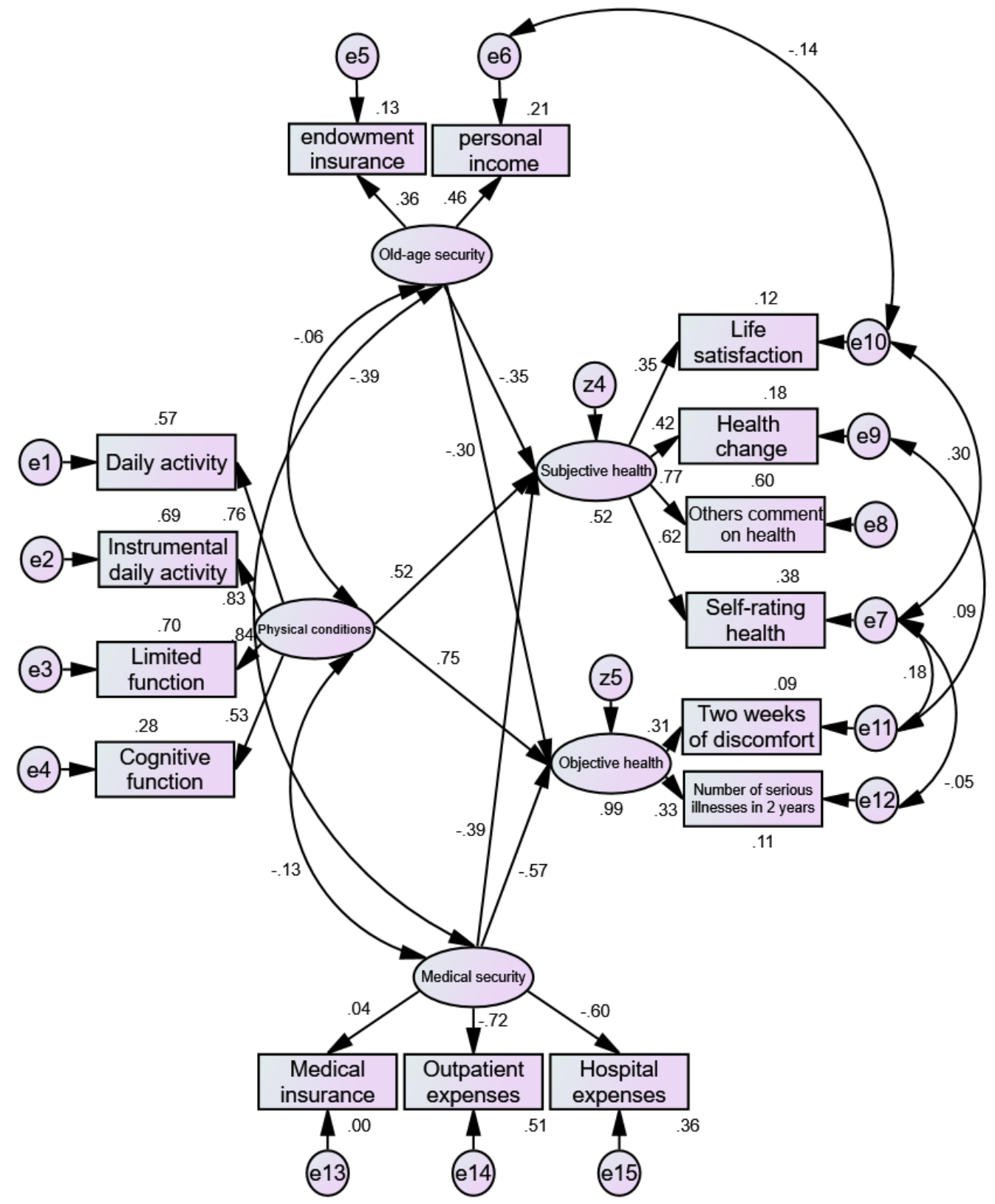

Fig.1 Parameter estimation results of the structural equation model 
In order to facilitate the understanding of the correlation between the model variables and compare the impact strength, Figure 1 shows the specific correlation and the normalization coefficient.

In order to express the correlation and comparison clearly, the normalization coefficient of the structural equation model is shown in Figure 1. The standardized regression coefficient of endowment insurance for subjective health is -0.352 , and the standardized regression coefficient of subjective health of medical insurance is -0.394. Specifically, old-age insurance and medical insurance are related to life satisfaction, health changes, other health assessments, and self-assessment. The regression coefficients for health were all significantly negative. This shows that both old-age security and medical security can improve the life satisfaction, health change, health assessment and self-assessment of the elderly surveyed. The standardized regression coefficient of old-age insurance for objective health is -0.302 , and the standardized regression coefficient of medical insurance for objective health is -0.571. Specifically, the regression coefficient of old-age insurance and medical insurance for two weeks of discomfort and the number of serious illnesses in two years Both are significantly negative. This shows that both old-age security and medical security can reduce the two-week discomfort rate of elderly people surveyed and the number of serious illnesses in two years.

From the perspective of the influence of various factors on the health status, there are certain similarities in the impact of old-age security and medical security on subjective health and objective health: in both subjective and objective health, medical insurance has a stronger effect. It can be seen that under current circumstances, medical security is still a key factor affecting the health of the elderly. The government must adopt a multi-pronged approach in formulating policies and investing funds. It must maintain a high level and efficient implementation of medical security, and optimize measures in multiple dimensions such as old-age security, so as to comprehensively improve the elderly's Level of health.

\subsection{Robustness test}

\subsubsection{Robustmess test of replacement sample data}

In order to test the robustness of the model, we replaced the survey data of CLHLS in 2011 for testing. From the table below, we can see that the regression coefficient of endowment insurance for subjective health is -0.912, while the regression coefficient of medical insurance for subjective health is -13.836 , the regression coefficient of old age insurance for objective health is -0.114 , and medical insurance for The regression coefficient of objective health was -4.89 . It can be verified here that the impact of medical security on the health level of the elderly is greater than that of old-age security. In the degree of fitting, only the index of NFI is lower than the standard, which indicates that the model's fitting level is acceptable.

Table 3 Structural equation model parameter estimation results( $\mathrm{N}=5867)$

\begin{tabular}{|c|c|c|c|c|}
\hline Model & Variable relationship & $\begin{array}{c}\text { Estimated } \\
\text { coefficient }\end{array}$ & $\begin{array}{c}\text { Standard } \\
\text { error }\end{array}$ & $\mathrm{P}$ \\
\hline \multirow{4}{*}{\begin{tabular}{c} 
A. $\begin{array}{c}\text { A.ructural } \\
\text { model }\end{array}$ \\
\cline { 2 - 5 }
\end{tabular}} & Old-age security $\rightarrow$ Subjective health & -0.912 & 0.127 & $0.000^{* * *}$ \\
\cline { 2 - 5 } & Old-age security $\rightarrow$ Objective health & -0.114 & 0.043 & $0.008^{* * *}$ \\
\cline { 2 - 5 } & Physical conditions $\rightarrow$ Subjective health & 0.240 & 0.010 & $0.000^{* * *}$ \\
\cline { 2 - 5 } & Physical conditions $\rightarrow$ Objective health & 0.073 & 0.005 & $0.000^{* * *}$ \\
\cline { 2 - 5 } & Medical security $\rightarrow$ Subjective health & -13.836 & 6.589 & $0.036^{* *}$ \\
\cline { 2 - 5 } & Medical security $\rightarrow$ Objective health & -4.809 & 2.310 & $0.037^{* *}$ \\
\hline
\end{tabular}


health The coefficient is-5.886. It can be verified here that the impact of medical security on the health level of the elderly is greater than that of old-age security. In the degree of fitting, all indicators meet the standard, which indicates that the model's fitting level is acceptable.

Table 5 Structural equation model parameter estimation results( $\mathrm{N}=4628)$

\begin{tabular}{|c|c|c|c|c|}
\hline Model & Variable relationship & $\begin{array}{l}\text { Estimated } \\
\text { coefficient }\end{array}$ & $\begin{array}{l}\text { Standard } \\
\text { error }\end{array}$ & $\mathrm{P}$ \\
\hline \multirow{8}{*}{$\begin{array}{c}\text { A. } \\
\text { Structural } \\
\text { model }\end{array}$} & $\begin{array}{c}\text { Old-age security } \rightarrow \text { Subjective } \\
\text { health }\end{array}$ & -1.070 & 0.151 & $0.000 * * *$ \\
\hline & $\begin{array}{c}\text { Old-age security } \rightarrow \text { Objective } \\
\text { health }\end{array}$ & -0.196 & 0.047 & $0.000 * * *$ \\
\hline & $\begin{array}{c}\text { Physical } \\
\text { conditions } \rightarrow \text { Subjective health }\end{array}$ & 0.223 & 0.011 & $0.000 * * *$ \\
\hline & $\begin{array}{c}\text { Physical } \\
\text { conditions } \rightarrow \text { Objective health }\end{array}$ & 0.074 & 0.005 & $0.000 * * *$ \\
\hline & $\begin{array}{c}\text { Medical security } \rightarrow \text { Subjective } \\
\text { health }\end{array}$ & -18.928 & 9.103 & $0.038^{* *}$ \\
\hline & $\begin{array}{c}\text { Medical security } \rightarrow \text { Objective } \\
\text { health }\end{array}$ & -5.886 & 2.851 & $0.039 * *$ \\
\hline & $\begin{array}{c}\text { Living habit } \rightarrow \text { Subjective } \\
\text { health }\end{array}$ & -0.001 & 0.028 & 0.984 \\
\hline & Living habit $\rightarrow$ Objective health & -0.021 & 0.012 & $0.094 *$ \\
\hline \multirow{4}{*}{$\begin{array}{c}\text { B. } \\
\text { Measurement } \\
\text { model }\end{array}$} & Living habit $\rightarrow$ Drinking & $1^{a}$ & & \\
\hline & Living habit $\rightarrow$ Drank & 0.758 & 0.020 & $0.000 * * *$ \\
\hline & Living habit $\rightarrow$ Smoking & 0.711 & 0.023 & $0.000 * * *$ \\
\hline & Living habit $\rightarrow$ Smoke & 0.479 & 0.018 & $0.000 * * *$ \\
\hline \multirow{2}{*}{$\begin{array}{l}\text { C. Fitting } \\
\text { indicators }\end{array}$} & \multicolumn{4}{|c|}{ GFI $=0.957 \quad$ AGFI $=0.930 \quad$ RMSEA $=0.065$} \\
\hline & \multicolumn{4}{|c|}{ NFI $=0.903 \quad$ IFI $=0.907 \quad$ CFI $=0.907$} \\
\hline
\end{tabular}

In general, the addition of more covariates and replacement of sample data did not change the direction and significance of the coefficients of the original model. The meaning of the coefficients is that the effect of medical security is greater. This verifies that the empirical results of this article are robust and reliable.

\section{Conclusions and policy recommendations}

Based on the survey data of CLHLS in 2014, using structural equation model, we can see that in China, both pension security and medical security have a significant impact on the health of the elderly, but compared with pension security, the current medical security system has a greater impact on the health of the elderly. This paper speculates that the main reason for this result is that although pension security and medical security have an impact on the health level of the elderly, the demand level of the elderly makes the improvement of the health level of the elderly still stay in the disease to be cured, and the disease prevention is still in the primary stage.

Therefore, under the current background of healthy China, our country should focus on the following aspects: first, the most concerned health problems of the elderly in our country are still treatable. We should improve the coverage rate and reimbursement level of medical insurance to meet the basic health needs of the elderly. At present, the popularization of medical insurance and the improvement of security level are still to improve the health of the elderly Important measures for health level. Secondly, in the aspect of old-age security, the pension provides part of the living allowance for the elderly, which not only protects the basic living standards of the elderly, but also 
gives the elderly the confidence to treat, and raises the level of the elderly's needs. Enabling the elderly to take an active interest in disease prevention, and the universalization and coverage of pensions is one of the key factors for the elderly to actively prevent and treat diseases. Third, based on meeting the current medical security needs of the elderly, the elderly are shifting from focusing on disease treatment to focusing on disease prevention, strangling the disease in its infancy, and preventing the disease from occurring or worsening. There is no need to suffer, nor to spend extra medical expenses. Promote the elderly to recognize the importance of disease prevention through publicity, attach importance to digitalization and informatization. Carry out offline publicity in the management at all levels, medical institutions, newspapers, TV and other media, and at the same time use the network, Wechat, blog and other platforms to achieve diversified publicity, so as to improve the elderly's awareness of health from online and offline.

It should be noted that the CLHLS data selected in this article belongs to the sample survey data, the survey population has limitations, and the factors that affect health are complex, but the model selection has limited impact factors. At the same time, the elderly surveyed also have awareness of their own health. There may be some misunderstandings. Regarding the above aspects, this article needs further expansion and research.

\section{References}

[1] The Sate Council. ,Outline of "Healthy China 2030".

[2] National Bureau of Statistics. Statistical Communiqué of the People's Republic of China on National Economic and Social Development 2017.

[3] Ministry of Finance Press Conference on Financial Revenue and Expenditure in the First Half of 2018.

[4] Jersey Liang., et al., Socioeconomic gradient in old age mortality in Wuhan, China. The Journals of Gerontology Series B: Psychological Sciences and Social Sciences, 2000, 55(4): p.S222-S233.

[5] CA Echevarría,A Iza. Life expectancy, human capital, social security and growth. Journal of Public Economics, 2006, 90 (12) :p.2323-2349.

[6] Zeng Xianxin. et al., The Effects of Social-Economic Status on the Mortality Hazard of Chinese Elderly. POPULATION \&ECONOMICS,2007 (5) :p.53-58.

[7] Huang Feng. ,et al., Estimating the Effects of Public Health Insurance on Mortality of the Elderly in Urban China. NANKAI ECONOMIC STUDIES, 2009 (6) :p.126-137.

[8] Zhang Su., et al., Healthy Aging and Service System for the Elderly. Teaching and Research 2013, V47 (11) :p.21-24.

[9] Wang Jun.,et al., A Review of Economics Analysis on the Elderly Health. Economic Research Journal, 2012 (1):p.134-150.

[10] Huang Jun. Research on the Relationship between Social and Economic Status, Social Security Treatment and Elderly Health-Based on the Dataset of China Household Income Survey. Social Security Studies, 2017 (6) :p.46-52.

[11] D Card., et al., The Impact of Nearly Universal Insurance Coverage on Health Care Utilization: Evidence from Medicare. American Economic Review, 2008 , 98 (5) :p.2242-2258.

[12] Huang Feng. ,et al., Excess Demand or Appropriate Demand?__Health Insurance, Medical Care and Mortality of the Elderly in Urban China. Economic Research Journal, 2010 (6) :p.105-119.

[13] Culter,D.M,E.R.Vigdor.,The Impact of Health Insurance on Health :Evidence from People Experiencing Health Shocks. NBER Working Paper,2005,p.16417.

[14] A Finkelstein,R Mcknight., What did Medicare do? The initial impact of Medicare on mortality and out of pocket medical spending.Journal of Public Economics, 2008, 92 (7) :p.1644-1668.

[15] Wang Xin jun.,et al., The Impact of Health Insurance on Medical Expenditure and Health of the Elderly. Journal of Finance and Economics .2014, 40 (12):p.65-75.

[16] Levy., et al., The Impact of Health Insurance on Health[J]. Annual Review of Public Health, 2008,29 (29):p.399.

[17] Zhao Zhong.,et al., Health Demand in Urban China and Grossman Model :

Evidence from Cross-sectional Analysis. Economic Research Journal, 2005 (10) :p.79-90.

[18] Pan Jie.,et al., Does Health Insurance Lead to Better Health?. Economic Research Journal, 2013 (4):p.130-142.

[19] Wu Lian can.,et al. Empirical Study on the Impact of New Rural Cooperative Medical System on Farmers' Health. INSURANCE STUDIES, 2010 (6) :p.60-68.

[20] H Wang., et al., The impact of rural mutual health care on health status: evaluation of a social experiment in rural 
China [J]. Health Economics, 2010, 18 (S2) :p.S65-S82.

[21] S Stringhini., et al., Association of socioeconomic position with health behaviors and mortality [J]. Jama, 2010, 303 (12):p.1159-1166.

[22] RG Wilkinson,. et al., Mortality, the Social Environment, Crime and Violence[J]. Sociology of Health \& Illness, 2010, 20 (5):p.578-597.

[23] Sudhir A nand., et al., Measuring disparities in health:Methods and Indicators[J]. Oxford University Press, 2001, p.49-67.

[24] Zhang Chong., et al., The Influences of Social Activities on Urban Elderly People's Health:Based on CHARLS 2011 ..POPULATION \&ECONOMICS, 2016 (5) :p.55-63.

[25] N Sirven,T Debrand. Social participation and healthy ageing: an international comparison using SHARE data[J]. Social Science \& Medicine, 2008, 67 (12) :p.2017-2026.

[26] Liu Chang ping., et al., Research on the Impact of Socioeconomic Status on the Health Status of the Elderly Chinese Journal of Population Science,2017 (5) :p.40-50. 